\title{
Retraction Note: A Nano-biosensors model with optimized bio-cyber communication system based on Internet of Bio-Nano Things for thrombosis prediction
}

\author{
H. Fouad - Mohamed Hashem • Ahmed E. Youssef
}

Published online: 14 August 2021

(C) Springer Nature B.V. 2021

Retraction Note to: J Nanopart Res (2020) 22:177

https://doi.org/10.1007/s11051-020-04905-8

The Editor-in-Chief and the Publisher have retracted this article. The article was accepted as part of a guest-edited special issue in Journal of Nanoparticle Research. Before the special issue was finalized, the Editor-in-Chief detected problems with editorial handling and peer review and decided not to proceed with the special issue [1].

The original article can be found online at https://doi.org/ 10.1007/s11051-020-04905-8.

\section{H. Fouad $(\bowtie)$}

Applied Medical Science Department, Community College, King Saud University, Riyadh, Saudi Arabia e-mail: menhfef@ksu.edu.sa

H. Fouad

Department of Biomedical Engineering, Faculty of Engineering, Helwan University, Helwan, Egypt

M. Hashem

Dental Health Department, College of Applied Medical

Sciences, King Saud University, Riyadh, Saudi Arabia

A. E. Youssef

College of Computer and Information Science, King Saud

University, Riyadh, Saudi Arabia

A. E. Youssef

Department of Computers and Systems Engineering,

Helwan University, Cairo, Egypt
Post publication peer review found that this article is out of scope for the journal, which focuses on original contributions on nanoscale phenomena and processes, and does not meet the standards required by the journal.

None of the authors agree to this retraction.

\section{References}

1. Pinna N, Clavel G, Roco MC (2020) The Journal of Nanoparticle Research victim of an organized rogue editor network! J Nanopart Res 22:376. https://doi.org/10.1007/ s11051-020-05094-0

Publisher's note Springer Nature remains neutral with regard to jurisdictional claims in published maps and institutional affiliations. 